\title{
THE ECONOMIC, ENERGY, AND EMISSIONS IMPACTS OF CLIMATE POLICY IN SOUTH KOREA
}

\author{
NIVEN WINCHESTER ${ }^{*, \dagger}, \dot{*}$ and JOHN M. REILLY* \\ *Joint Program on the Science and Policy of Global Change \\ Massachusetts Institute of Technology \\ Cambridge, MA 02139, USA \\ ${ }^{\dagger}$ Motu Economic and Public Policy Research \\ Level 1, 97 Cuba Street, Wellington 6142, New Zealand \\ niven@mit.edu
}

Accepted 14 May 2019

Published 4 July 2019

\begin{abstract}
Using an economy-wide model, we evaluate the impact of policies to meet South Korea's Paris pledge to reduce greenhouse gas (GHG) emissions by $37 \%$ relative those under business as usual (BAU) in 2030. Simulated BAU emissions in 2030 are 840.8 million metric tons (Mt) of carbon dioxide equivalent $\left(\mathrm{CO}_{2} \mathrm{e}\right)$, indicating that economy-wide emissions should be constrained to $529.7 \mathrm{MtCO}_{2} \mathrm{e}$. Under South Korea's Emissions Trading System (KETS) and fuel economy standards, a 2030 carbon price of $\$ 88 / \mathrm{tCO}_{2} \mathrm{e}$ is needed to meet this goal. Without considering benefits from avoided climate damages, these policies reduce 2030 GDP by $\$ 21.5$ billion $(1.0 \%)$ and consumer welfare by 8.1 billion $(0.7 \%)$. Declines in sectoral production are largest for fossil-based energy sectors and chemical, rubber and plastic products, and iron and steel sectors.
\end{abstract}

Keywords: Emissions trading system; Paris agreement; fuel economy standard.

\section{Introduction}

At the 2015 Paris Climate Conference - the 21st Conference of the Parties (COP21) under the United Nations Framework Convention on Climate Change (UNFCC) South Korea joined most other countries in signing an agreement to mitigate greenhouse gas (GHG) emissions, extending earlier commitments for reductions through 2020 to 2030. Nations that are parties to the Paris agreement are required to submit National Determined Contributions (NDCs) that outline future reductions in GHG emissions out to 2030 .

\footnotetext{
¥Corresponding author.
}

This is an Open Access article published by World Scientific Publishing Company. It is distributed under the terms of the Creative Commons Attribution 4.0 (CC BY) License which permits use, distribution and reproduction in any medium, provided the original work is properly cited. 
South Korea has been actively developing a climate policy strategy since at least 2009 when it set a goal of reducing greenhouse gas (GHG) emissions by $30 \%$ below its business-as-usual (BAU) emissions level by 2020 as a part of its Nationally Appropriate Mitigation Action (NAMA). Based on its projected BAU level, that would leave emissions at 543 million tons of $\mathrm{CO}_{2} \mathrm{e}$, about $4.5 \%$ below its 2005 emissions level of 569 million tons (Ministry of the Environment, 2017). In June 2015, South Korea replaced the NAMA with the new goal of reducing greenhouse gas (GHG) emissions by $37 \%$ below BAU emissions by 2030 as a part of its 2030 Nationally Determined Contribution (NDC) target. An evaluation by Climate Action Tracker (2017) sees the replacement of the NAMA with the NDC as backsliding. While the NDC includes a slightly larger percentage reduction in emissions in 2030 from the BAU, the absolute level of emissions would be little different from the NAMA goal for 2020, emphasizing how interpretations of a target can vary depending on a focus on a reduction from BAU or an absolute reduction from an historic year. Climate Action Tracker (2017) also points out that 2030 emissions will be $81 \%$ above 1990 levels, reflecting very rapid growth between 1990 and 2012.

Projections given current policies indicate that South Korea's emissions will remain above the 2020 target, and additional new policies will be needed to achieve the 2030 goal. The government indicated that a $25.7 \%$ reduction will be achieved domestically and a further $11.3 \%$ reduction will be achieved by international market mechanisms (Climate Action Tracker, 2017). To meet these goals, South Korea launched three major policies: a Target Management Scheme (TMS), an Emission Trading Scheme (ETS), and 2020 Corporate Average Fuel Economy (CAFE) Regulations. The TMS is a precursor to the ETS, with lower penalties for noncompliance. CAFE regulations were introduced in 2014, with targets to be fully phased in by 2020 .

In this paper, we develop and deploy a custom-made economy wide model to evaluate the impacts of key climate policies in South Korea in 2030. Several studies focus on the global implications of the Paris agreement (Fawcett et al., 2015; Aldy et al., 2016; Vandyck et al., 2016; Jacoby et al., 2017). While these studies provide regional details, they typically do not report results for South Korea or assume costminimizing attainment of the NDC emissions goals, rather than specific policy proposals.

Yongrok et al. (2017) use an economy-wide model to examine the economic and emissions impacts of the South Korean ETS (KETS), but their analysis differs from ours in several ways. First, Yongrok et al. (2017) evaluate outcomes in 2015 and our analysis considers 2030. Secondly, the authors simulate emission reductions in sectors covered by the KETS without imposing an economy-wide emissions target. Thirdly, Yongrok et al. (2017) specify a single (aggregated) electricity technology while we explicitly represent eight different electricity generation technologies. Fourth, Yongrok et al. (2017) only consider $\mathrm{CO}_{2}$ emissions from fossil fuel combustion, whereas our modeling framework includes all GHGs covered by the policy. Fifth, we evaluate the KETS accounting for the impact of South Korea's fuel economy standard, whereas 
Yongrok et al. (2017) do not consider complementary measures. To our knowledge, our study is the first detailed economy-wide analysis of South Korea's 2030 NDC emissions pledge.

This paper has four further sections. Section 2 provides a further overview of key climate policies in South Korea. Section 3 describes the structure and data sources for our economy-wide model and the scenarios implemented in our analysis. Our results are presented and discussed in Sec. 4. Section 5 concludes.

\section{Climate Policy in South Korea}

Key climate policy legislation in South Korea includes the KETS and fuel economy standards. The long-term goal of the KETS is to reduce 2030 emissions by $37 \%$ relative to BAU. The foundations for the cap-and-trade system were set by The Framework Act on Low Carbon, Green Growth (Framework Act) in May 2012. The KETS was launched in January 2015 and is divided into three phases: Phase I runs from 2015 to 2017, Phase II operates from 2018 to 2020, and Phase III covers the period 2021 to 2025. In each phase, the cap on GHG emissions and rules concerning the operation of the system (e.g., the allocation of emission allowances and the use of offsets) can differ. In phase I, the cap on emissions is $573 \mathrm{MtCO}_{2} \mathrm{e}$ in 2015 , dropping to 562 in 2016 and to 551 in 2017. Emissions caps for subsequent phases have not yet been set.

Sectors covered by the KETS include (1) electricity, (2) industry (e.g., mining, oil refining, food and beverages, cement, steel, nonferrous metals, automobiles, shipbuilding, electronic equipment), (3) building (including telecommunication), (4) domestic aviation, and (5) public waste treatment. GHGs included in the KETS include emissions of carbon dioxide $\left(\mathrm{CO}_{2}\right)$, methane $\left(\mathrm{CH}_{4}\right)$, nitrous oxide $\left(\mathrm{N}_{2} \mathrm{O}\right)$, hydrofluorocarbons (HFCs), and sulfur hexafluoride $\left(\mathrm{SF}_{6}\right)$ from energy, industrial processes, product use and waste. Emissions from land use, land-use change, and forestry (LULUCF) are not currently included in the KETS.

In Phase I, there will be $100 \%$ free allocation of allowances, with allocations based on firm activities in 2011-2013. In subsequent phases, a proportion of allowances will be auctioned, with at least 10\% of allowances auctioned in Phase III. Energy-intensive, trade-exposed sectors will receive $100 \%$ of their allowances for free in all phases. Banking of emission permits is allowed without any restrictions. Borrowing permits is only allowed within each phase, with restrictions on the amount that can be borrowed. In all phases, up to $10 \%$ of emission rights can be sourced from outside the ETS in the form of offsets. In Phases I and II, only domestic offset credits can be used for ETS compliance. In Phase III, up to $50 \%$ of offsets can be sourced internationally (i.e., international offsets can contribute up 5\% of the total number allowances submitted for compliance obligations).

In our analysis, we evaluate the KETS in 2030 under the stated objective of reducing BAU emissions by $37 \%$ in this year. Our representation of the policy in 2030 
is guided by legislation for Phase III of the KETS, or where specifics for Phase III are yet to be set, the latest year for which legislation has currently been set. We do not consider banking and borrowing of emission permits in our analysis as evaluating these mechanisms would require emissions caps for each year out to 2030. The representation of the KETS in our modeling framework is described in Sec. 2.

South Korea's Ministry of Environment introduced new fuel economy and GHG standards for passenger cars, buses with a maximum seating capacity of 15 or fewer persons, and trucks that weigh less than 3.5 tons (ICCT, 2015). The regulations will be phased-in from 2016 to 2020 . They require a $30.7 \%$ reduction in the fleet average GHG emission for passenger vehicles from 2015 levels. Similar to regulations in the EU, some classes of very efficient vehicles are weighted more heavily. For example, zero emission vehicles get a weight of 3 and vehicles with less than $50 \mathrm{~g} / \mathrm{km}$ of GHGs get a weight of 2. Light trucks and buses are required to reduce their GHG emissions by $15.2 \%$ from 2013 to 2020 , with the actual standard varying by gross curb weight of the vehicle (i.e., each curb weight must meet the $15.2 \%$ improvement from 2013 levels, recognizing that heavier vehicles have higher emissions per kilometer). The Korea Energy Management Corporation on behalf of the Ministry of Trade, Industry, and Energy introduced a nearly equivalent set of fuel economy standards.

Vehicle manufacturers can select by the end of March each year whether to achieve the average fuel economy standard or the GHG emission standard. The manufacturer can also choose either a sales ratio target or a yearly target for passenger cars and light trucks (Ministry of Environment, 2014). The sales ratio target requires that $10 \%$ of

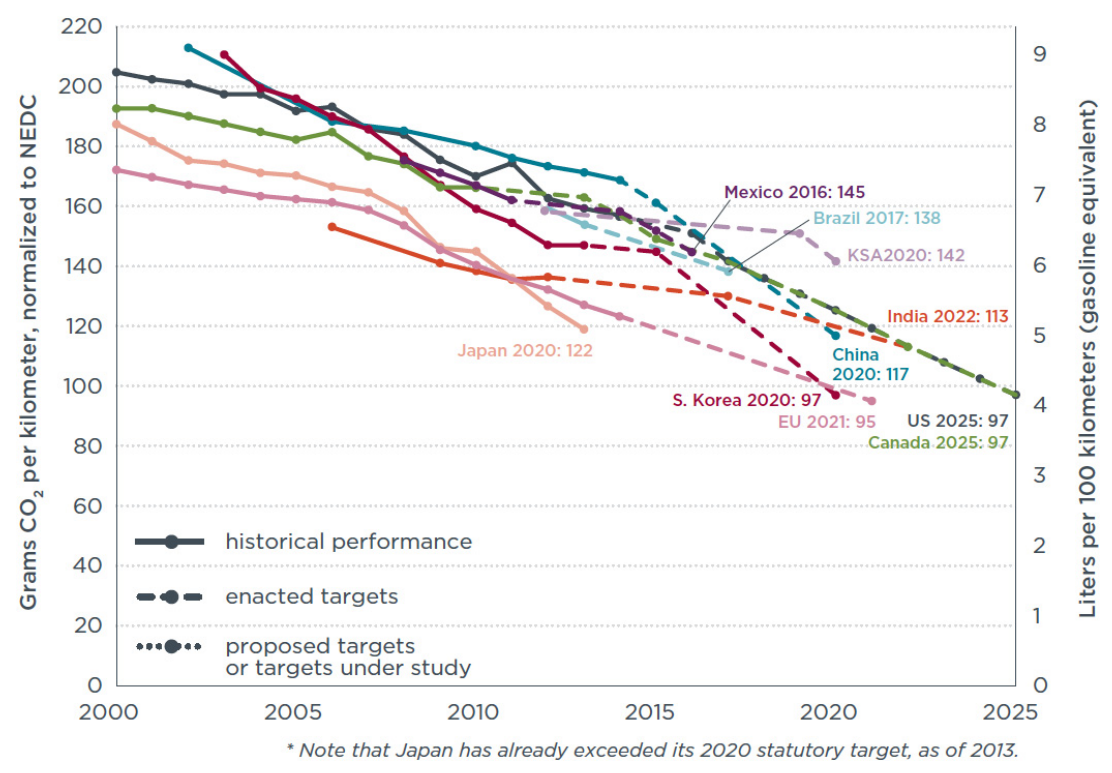

Source: ICCT (2015).

Figure 1. Global $\mathrm{CO}_{2}$ emissions standards for passenger vehicles. 
vehicles sold in 2016 must meet the 2020 targets, with this percentage increasing to $20 \%$ by $2017,30 \%$ by $2018,60 \%$ by 2019 , and $100 \%$ by 2020 (ICCT, 2015). If a manufacturer chooses the yearly target, the total manufactured cars in the corresponding year are required to produce $127 \mathrm{~g} / \mathrm{km}$ or less GHG by $2016,123 \mathrm{~g} / \mathrm{km}$ or less GHG by $2017,120 \mathrm{~g} / \mathrm{km}$ or less GHG by $2018,110 \mathrm{~g} / \mathrm{km}$ or less GHG by 2019 , and $97 \mathrm{~g} / \mathrm{km}$ or less GHG by 2020 on average (Ministry of Environment, 2014).

South Korea's targets are among the most stringent in the world (Fig. 1). The emissions standard in the European Union (EU) is $95 \mathrm{gCO}_{2} / \mathrm{km}$ emission and is nominally the most stringent, however, an important consideration is how the standard is tested. The EU standard produces significantly lower emissions than achieved under average actual driving conditions. South Korea uses the US test standards which are more closely calibrated to actual driving averages. Factoring in the test standard difference makes South Korea's standard more stringent than Europe's.

Climate Action Tracker (2017) concludes that current policies in South Korea will be insufficient to meet the NDC target, and hence further tightening of policies would be required to meet it. South Korea has not set fuel economy targets beyond 2020 at this point.

\section{Methods}

\subsection{Modeling framework}

Our analysis develops a bespoke multisector applied general equilibrium model of economic activity, energy, and GHG emissions tailored to South Korea. The model links South Korea to the rest of the world via sectoral imports and exports, and sectors are interconnected by purchases of intermediate inputs. The model is static with a forward calibration to 2030. That is, the model is calibrated using data for a base year (2011), a baseline scenario is created for 2030, and then the model is simulated under alternative policy shocks to provide estimates of policy costs and outcomes for 2030 but it does not estimate outcomes for intermediate time periods. This contrasts to dynamic models, which estimate periodic, usually annual, outcomes.

The model links sectoral production to emissions of $\mathrm{CO}_{2}, \mathrm{CH}_{4}, \mathrm{~N}_{2} \mathrm{O}$, and aggregated fluorinated gases (F-gases: HFCs, $\mathrm{PFCs}$, and $\mathrm{SF}_{6}$ ) from the combustion of fossil fuels, industrial processes, agriculture, and waste. ${ }^{1}$ The 35 sectors represented in the model are listed in Table 1. The model represents 13 sectors related to energy extraction, production and distribution, including eight electricity generation technologies. Transportation is represented by separate commercial and household transportation (transportation in own-supplied vehicles and household purchases of commercial transportation) sectors. The model also represents 13 manufacturing sectors and five nontransportation service sectors.

${ }^{1}$ The model does not include emissions from land use, land-use change, and forestry (LULUCF). 
Table 1. Sectoral aggregation.

\begin{tabular}{|c|c|c|c|}
\hline \multicolumn{2}{|c|}{ Energy extraction, production, and distribution } & \multicolumn{2}{|c|}{ Manufacturing } \\
\hline $\mathrm{cru}$ & Crude oil extraction* & $\operatorname{crp}$ & Chemical, rubber, and plastic products* \\
\hline oil & Refined oil products* & $\mathrm{nmm}$ & Nonmetallic minerals* \\
\hline $\operatorname{col}$ & Coal extraction* & i_s & Iron and steel* \\
\hline gas & Natural gas extraction and distribution* & $\mathrm{nfm}$ & Nonferrous metals* \\
\hline ecoa & Coal electricity* & fmp & Fabricated metals products* \\
\hline egas & Gas electricity* & fod & Food processing* \\
\hline eoil & Oil electricity* & w_p & Wood and paper products* \\
\hline enuc & Nuclear electricity* & tcf & Textiles, clothing, and footwear* \\
\hline ehyd & Hydroelectricity* & $\mathrm{mvh}$ & Motor vehicles and parts* \\
\hline ewin & Wind electricity* & otn & Other transportation equipment* \\
\hline esol & Solar electricity* & ele & Electronic equipment* \\
\hline eoth & Other electricity* & ome & Other machinery and equipment* \\
\hline tnd & Electricity transmission and distribution* & omf & Other manufacturing* \\
\hline \multicolumn{2}{|c|}{ Other primary production } & \multicolumn{2}{|c|}{ Other services } \\
\hline $\operatorname{agr}$ & Agriculture, forestry, and fishing & $\operatorname{trd}$ & Wholesale and retail trade \\
\hline omn & Other mining* & & Water collection and distribution* \\
\hline & & $\mathrm{cmn}$ & Communications* \\
\hline \multicolumn{2}{|c|}{ Transportation } & $\mathrm{cns}$ & Construction* \\
\hline hht & Household transportation & ser & Other Services \\
\hline $\operatorname{trn}$ & Commercial transportation & & \\
\hline
\end{tabular}

Note: *Model sectors included in the Korean ETS.

In each sector, there is a representative firm that produces output by hiring primary factors and purchasing intermediate inputs from other firms. Production in each sector is represented by a multi-level nest of constant elasticity of substitution (CES) functions. Nesting structures for sectoral groups are outlined in Figs. 2-5. All sectors

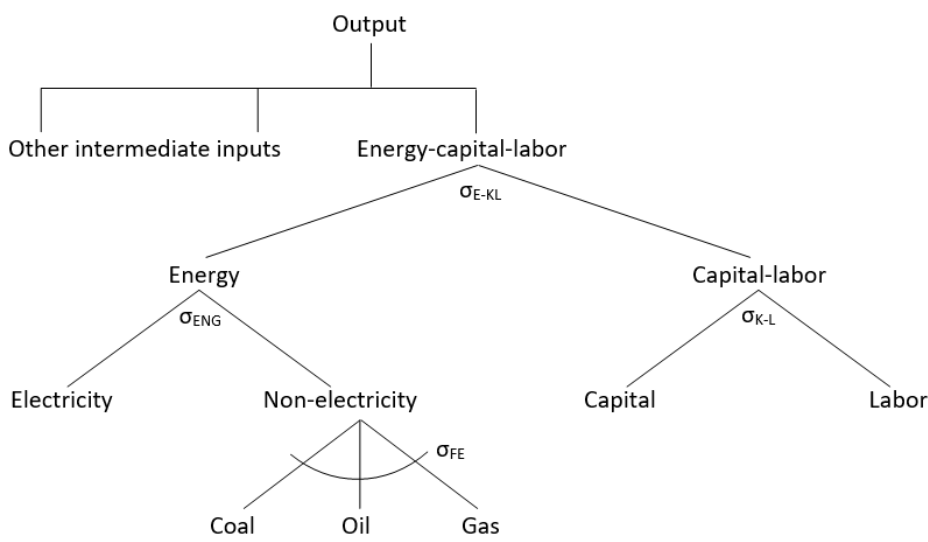

Note: Vertical lines in the input nest signify a Leontief or fixed coefficient production structure in which the elasticity of substitution is zero.

Figure 2. Production nest for all sectors except electricity, mining, and agriculture. 


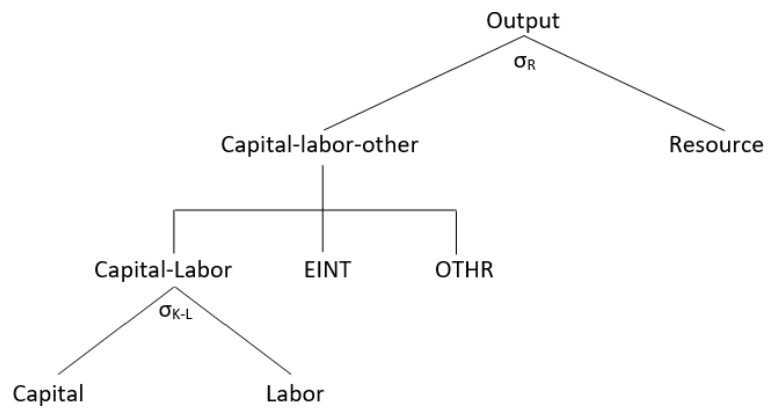

Note: See notes to Fig. 2.

Figure 3. Production nest for mining sectors.

except fossil fuel extraction, electricity production, and agriculture are built on the production structure described in Fig. 2. A key feature of the production nest is substitution between aggregate energy and a capital-labor composite, which allows price-induced improvements in energy efficiency. Other opportunities to abate emissions are provided by the ability to substitute between electricity and (in aggregate) nonelectricity energy, and among nonelectricity energy inputs (coal, gas, and refined oil). The top-level nest combines nonenergy intermediate inputs with the energy-value added composite using a Leontief aggregation. Mining activities, including fossil fuel extraction sectors, are produced by a CES aggregate of a sector-specific resource (e.g., coal resources for the coal sector) and a composite of capital, labor and intermediate inputs (Fig. 3).

In fossil-based electricity sectors (Fig. 4(a)), there is substitution between fuel inputs and a capital-labor aggregate to capture price-induced improvements in energy conversion efficiency. There is also the potential for fuel-switching within each fossil-fuel electricity sector, but substitution among fuels is limited by the small (or zero) share of other fossil fuels used in each fossil electricity sector. ${ }^{2}$

A key characteristic of nonfossil electricity sectors is the aggregation of a technology specific factor and (aggregated) other inputs in the top level of each production nest (Fig. 4(b)). For nuclear electricity and hydroelectricity, which are largely determined by regulations, the top-level elasticity is set equal to zero. This feature allows output for these sectors to be assigned exogenously via endowments of the technologyspecific factors. For other nonfossil electricity sectors (wind, solar, and other electricity), top-level elasticity values capture constraints due to intermittency and resource availability, while at the same time allowing production of these technologies to respond to price changes. This representation leads to rising marginal generation costs and limits penetration of each technology.

\footnotetext{
${ }^{2}$ In the base data, coal electricity and oil electricity are exclusively produced from, respectively, coal and refined oil. Gas electricity uses mostly gas and a small amount of refined oil.
} 


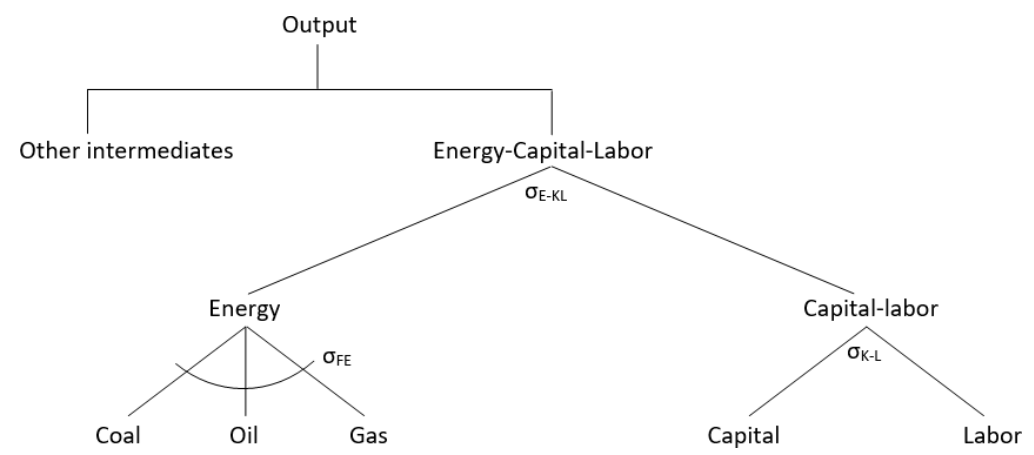

(a) Fossil electricity

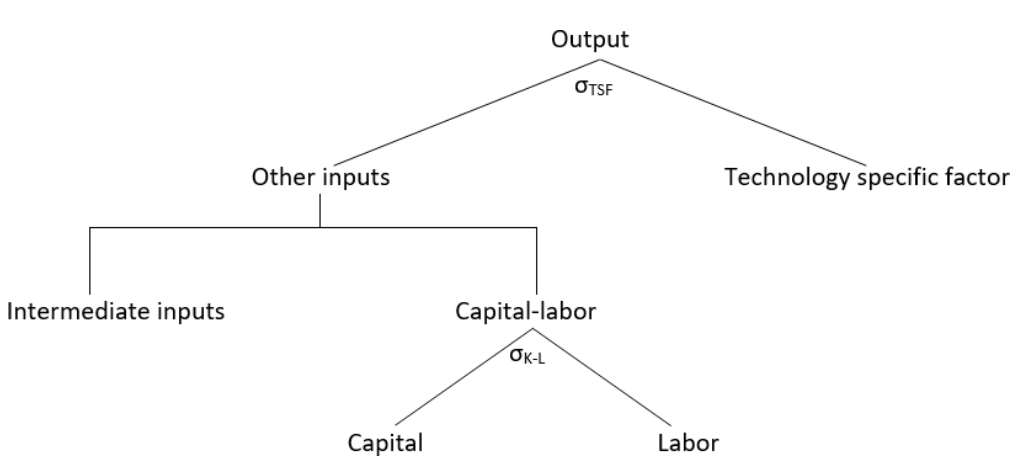

(b) Nonfossil electricity

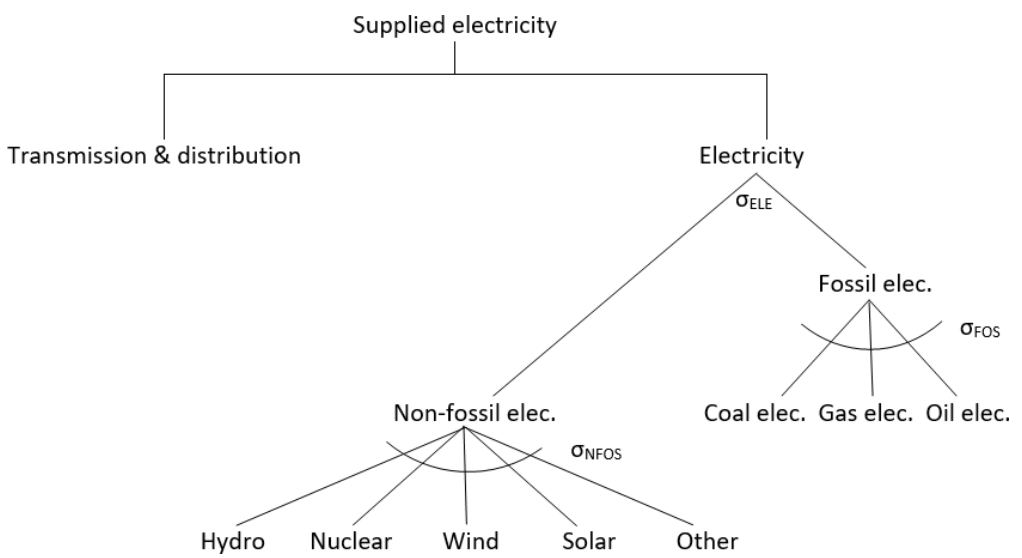

(c) Supplied electricity

Note: See notes to Fig. 2.

Figure 4. Production nests for (a) fossil electricity, (b) nonfossil electricity, and (c) supplied electricity. 


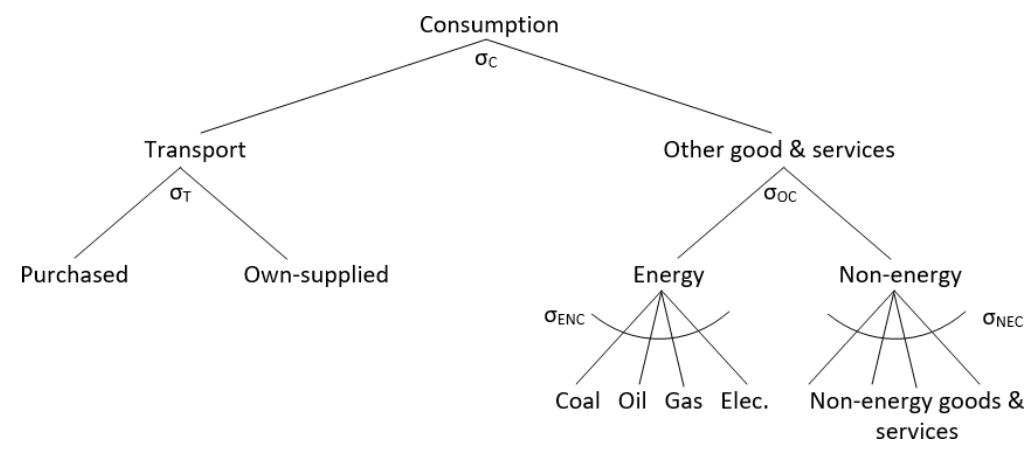

(a) Consumption

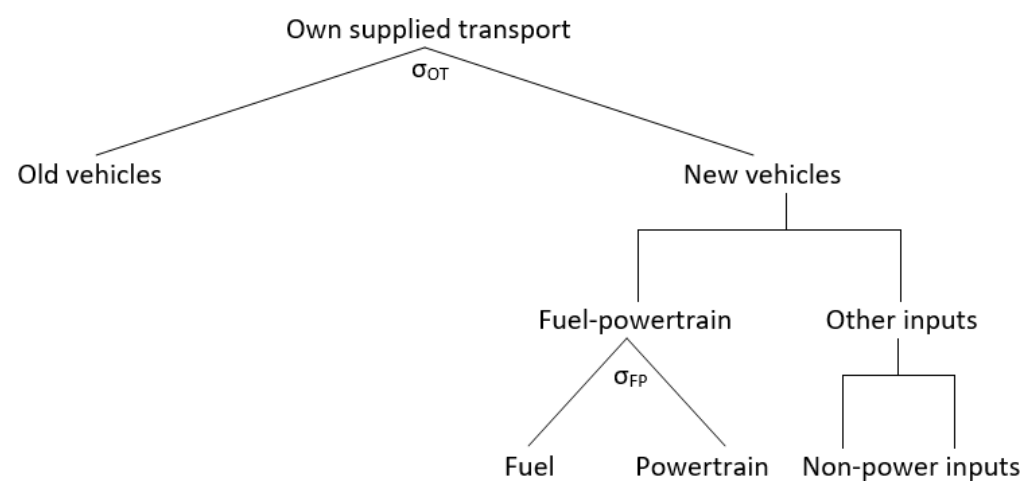

(b) Own-supplied transport

Note: See notes to Fig. 2.

Figure 5. Nesting structure for (a) consumption and (b) own-supplied transport.

Other studies that use technology-specific factors to control for intermittency (and other) factors not explicitly represented in economy-wide models include Orlov and Aaheim (2017) and Singh et al. (2017). An advantage of this approach is that it facilitates exogenous assignment of generation from these technologies to meet external forecasts in the BAU scenario, while at the same time allowing price-induced changes in generation in the policy scenarios. An alternative approach is to include intermittent electricity sources as imperfect substitutes for other types of electricity (Chen et al., 2017). Under this approach, as in a technology-specific factor specification, the marginal 'cost' of adding an additional unit of intermittent generation is increasing, but it is difficult to impose external generation estimates in the BAU scenario. Outside the scope of our study, another approach is to link the economy-wide model with an electricity model that represents hourly electricity demand and supply by technology (Rausch and Mowers, 2014).

To produce supplied electricity (which is purchased by firms and consumers), fossil electricity types and nonfossil electricity outputs are combined using separate CES 
functions, and the two aggregates are combined using a further CES function (Fig. 4(c)). In this nesting structure, nonfossil electricity sources are perfect substitutes for each other, and aggregate fossil fuel electricity is a perfect substitute for nonfossil electricity $\left(\sigma_{\mathrm{ELE}}=\sigma_{\mathrm{NFOS}}=\infty\right)$, but the supply-side constraints noted above prevent one technology from suppling the whole market. Aggregate electricity is combined with transmission and distribution in a Leontief nest.

A representative agent derives income from selling factor services and allocates expenditure across private consumption, government consumption, and saving/ investment. The nesting structure for final consumption is outlined in Fig. 5. Important features of the specification include substitution among goods with different GHG intensities and a detailed representation of household transportation. The household transportation specification allows substitution between purchased transportation (supplied by the commercial transport sector) and own-supplied transportation. Building on Karplus et al. (2013), own-supplied transportation distinguishes old and new vehicles and breaks down new vehicles into several components based on the services they provide. Importantly, substitution between powertrain capital and refined oil inputs used in new vehicles reflects the scope for consumers to purchase more fuelefficient cars, at a higher cost, in response to increases in the price of fuel and/or policies. A mandated maximum amount of fuel per kilometer of travel services (to represent a fuel economy standard) is specified using a powertrain certificate system. In this system, powertrain capital used for the production of new cars is allocated one certificate per unit of output, and both powertrain capital and refined oil require $\varphi$ certificates to be used in new car production. Under this system, the share of fuel inputs in transport services from new cars is $(1-\varphi) \gamma$, where $\gamma$ is the share of the fuelpowertrain aggregate in transport services from new cars. As the fuel-powertrain aggregate is combined with other inputs using a Leontief function, $\gamma$ is fixed and a fuel economy standard can be imposed by setting the value for $\varphi$. If a fuel economy standard is not simulated, the powertrain certificate system is turned off in the model.

A government sector collects taxes and provides subsidies and purchases goods and services. Net fiscal deficits and, where applicable, revenue from the sale of emission permits are passed to consumers as (implicit) lump sum transfers. Although the model is static, investment is included as a proxy for future consumption and is a fixed proportion of expenditure by each regional household.

$\mathrm{CO}_{2}$ emissions from fossil fuels are included in the model in fixed proportion with the use of each fossil fuel. $\mathrm{CO}_{2}$ emissions from industrial processes and non- $\mathrm{CO}_{2}$ emissions (noncombustion GHGs) are linked to output in each sector. Noncombustion GHGs per unit of output decrease in future years according to assumed autonomous improvements in GHG intensities. When there is a carbon price, total inputs trade-off with noncombustion GHGs according to a CES function in each sector, allowing abatement of emissions by using more other inputs.

Elasticity values in production and consumption in the model are guided by those used in the MIT Economic Projection and Policy Analysis (EPPA) model 
(Paltsev et al., 2005; Chen et al., 2017) and the European Commission's General Equilibrium Model for Economy-Energy-Environment (GEM-E3; Capros et al., 2013). In turn, elasticity parameters in the EPPA model are informed by a literature review of econometric estimates and expert elicitation by Cossa (2004), whereas those in GEM-E3 are shaped by econometric estimates by Fragkiadakis et al. (2012). Elasticity values in both models are assigned uniformly across countries, however, as the ability to substitute among inputs is also determined by input cost shares, substitution possibilities in our model are calibrated to reflect characteristics of the South Korean economy.

International trade in goods and services follows the 'Armington approach' that assumes that goods are differentiated by country of origin (Armington, 1969). Specifically, for each commodity, domestic production is differentiated from imports using a CES function. Values for elasticities of substitution in the trade specification are sourced from (Hertel et al., 2007). Also for each commodity, production is allocated across the domestic market and exports using a constant elasticity of transformation function.

Turning to closures, the current account deficit is fixed proportion of GDP; factor prices are endogenous and there is full employment; labor and new capital (capital installed between 2011 and 2030) are mobile across sectors; capital installed in the base year (2011) is subject to 5\% per annum depreciation rate and is sector-specific; and technology/sector-specific resources are immobile across sectors.

The model is calibrated using the Global Trade Analysis Project (GTAP) Power Database (Peters, 2016). This database augments version 9 of the GTAP Database (Aguiar et al., 2016) and includes economic data and $\mathrm{CO}_{2}$ emissions from the combustion of fossil fuels for 140 regions and 68 sectors. We extract the data for South Korea and aggregate the sectors to those listed in Table 1 by extending tools provided by Lanz and Rutherford (2016). We also augment GTAP-Power with data on non- $\mathrm{CO}_{2}$ emissions from Irfanoglu and van der Mensbrugghe (2015) and estimates of noncombustion $\mathrm{CO}_{2}$ emissions from Greenhouse Gas Inventory and Research Center of Korea (2014). The base data for the model provides a snapshot of South Korea in 2011.

The model is formulated and solved as a mixed complementarity problem using the Mathematical Programming Subsystem for General Equilibrium (MPSGE) described by Rutherford (1995) and the Generalized Algebraic Modeling System (GAMS) mathematical modeling language Rosenthal (2012) with the PATH solver (Dirkse and Ferris, 1995).

\subsection{Scenarios}

Table 2 summarizes the five scenarios considered in our analysis. The first, Benchmark, requires no simulation and simply reports economic, energy, and emission outcomes for South Korea in 2011, as measured by the database used to calibrate the model. Remaining scenarios simulate outcomes for 2030. Our BAU simulation creates 
Table 2. Scenarios.

\begin{tabular}{ll}
\hline Name & \multicolumn{1}{c}{ Description } \\
\hline Benchmark & South Korea economy as represented by the benchmark data in 2011 \\
BAU & South Korea in 2030 under 'Business as usual' (no climate policies) \\
ETS & Implementation of the KETS (with offsets) to meet South Korea's 2030 NDC pledge \\
ETS-Vehicles & ETS with fuel economy standards for new vehicles \\
ETS-All & An all-sectors ETS (with offsets) to meet South Korea's 2030 NDC pledge \\
\hline
\end{tabular}

projections for economic, energy, and GHG emission outcomes in South Korea in 2030 under a hypothetical 'no climate policy' or 'business as usual' case. Key inputs for our BAU simulation include (1) the assignment of technology-specific factor endowments for certain electricity sectors, (2) changes in fossil fuel prices, (3) autonomous energy efficiency improvements, (4) autonomous improvements in noncombustion GHG intensities, and (5) an exogenous GDP target (met via endogenous changes in total factor productivity).

Our assignments for technology-specific factors for electricity generation types, which drive output from these technologies, are informed by 'Reference case projections for electricity capacity and generation by fuel (2015-50)' from EIA (2017). Fossil fuel price forecasts are also guided by EIA (2017), which reflect global supply and demand for fuels and the scarcity of fossil resources. We assume that South Korea faces a perfectly elastic import supply curve for fossil fuels at these prices. We impose autonomous energy efficiency improvements of $1.5 \%$ per year in fossil fuel use and a $0.3 \%$ annual efficiency improvement in electricity use. The BAU also simulates autonomous decreases in noncombustion GHG (both $\mathrm{CO}_{2}$ and non- $\mathrm{CO}_{2}$ ) emissions per unit of output of $1.5 \%$ per year. Total factor productivity improvements in the BAU scenario are determined endogenously to target 2030 GDP estimates from OECD (2017). Under this estimate, GDP in South Korea increases by $73.9 \%$ between 2011 and 2030, which implies a cumulative annual average growth rate of $2.95 \%$. In the policy scenarios, total factor productivity parameters are exogenous (and equal to values derived in the BAU scenario) and GDP is endogenous.

In the ETS scenario, we implement an emissions trading system across covered sectors that reduces economy-wide emissions in South Korea by 37\% relative to those in the BAU scenario (i.e., meets South Korea's 2030 NDC pledge). The ETS includes 30 of the 35 sectors in the model (Table 1) and covers all GHG emissions with trading across gases and sectors. ${ }^{3}$ As the ETS targets a reduction in economy-wide emissions but does not cover all sectors, the emissions cap on covered sectors is chosen endogenously in the model to target a desired level of economy-wide emissions.

\footnotetext{
${ }^{3}$ The GTAP database does not differentiate domestic and international aviation, so a limitation of our work is that domestic aviation (included in the commercial transportation sector in the model) is not included in the ETS.
} 
As noted earlier, up to $10 \%$ of emissions rights can be sourced from outside the ETS. We model the supply of domestic offsets using a (secondary) cap-and-trade program for all sectors not included in the ETS (except fossil fuels purchased by households) with a BAU emissions cap. Under this system, emission reductions by non-KETS sectors below the BAU level create domestic offsets that can, up to a certain limit, be used for compliance with the KETS. Guided by the median offset price used by ICAO-CAEP (2016), we assume that international offsets in 2030 are available at a fixed price of $\$ 15 / \mathrm{tCO}_{2} \mathrm{e} .^{4}$

We model the use of total offsets and international offsets with two (pseudo) certificate schemes to ensure that the limits on offset use are enforced. Specifically, to use an (domestic or international) offset to meet ETS obligations for one ton of emissions, an entity must turn in an offset credit for one ton of emissions and one 'offset certificate'. To use an international offset, in addition to providing an offset credit for one ton of emissions and an 'offset certificate', an entity must hand over one 'international certificate'. On the supply side, certificates are 'produced' in fixed proportions with ETS permits: for each permit for one ton of emissions there are $\alpha$ 'offset certificates' and $\alpha \theta$ 'international certificates'. By setting $\alpha=0.1$ and $\theta=0.5$, we impose the upper limits on the use of total offsets and international offsets set out in the KETS (offsets can be used to meet up to $10 \%$ of obligations to surrender emissions rights, and international offsets can contribute up to $50 \%$ of the total amount of offsets). As total emissions allowed from sectors included in the ETS are endogenous (the cap on emissions from these sectors is adjusted to target economy-wide emissions), maximum limits on the supply of offsets (in tons) are also endogenous in the model.

In the ETS-Vehicles scenario, we impose a fuel economy standard for new vehicles in addition to the policies in the ETS scenario. Current legislation mandates fuel consumption per kilometer for cars of $31.1 \%$ by 2020 relative to a 2013 baseline. We assume the fuel economy standard continues to be tightened beyond the 2020 mandate by extending to 2030 the same annual rate of improvement between 2013 and 2020 . This results in an estimated reduction in fuel consumption per kilometer of $59.5 \%$ relative to 2013.

The final scenario, ETS-All, simulates an ETS covering all sectors, including the household, to meet South Korea's 2030 NDC pledge without fuel economy standards. The scenario allows international offsets to account for up to 5\% of domestic ETS permits and, as the ETS is economy-wide, there are no domestic offsets. This scenario provides an estimate of a first best/least cost policy (subject to the limit on international offsets) to meet South Korea's stated emissions reduction.

\footnotetext{
${ }^{4}$ One source of international credits for KETS compliance is the EU ETS; however, as 2030 carbon prices in both South Korea and the EU are expected to be higher than those in most other regions (Vandyck et al., 2016, Table 9), international credits are likely to be sourced from other regions.
} 


\section{Results}

A summary of results for each scenario is presented in Table 3, with additional results reported in Table 4 (GHG emissions by gas), Table 5 (electricity generation by technology), Table 6 (primary energy by fuel), and Table 7 (sectoral output). Under BAU, the exogenously imposed $73.9 \%$ increase in GDP between 2011 and 2030 drives an increase in GHG emissions of $24.2 \%$ (from $677.1 \mathrm{MtCO}_{2} \mathrm{e}$ in 2011 to $840.8 \mathrm{MtCO}_{2} \mathrm{e}$ in 2030). ${ }^{5}$ The proportional increase in emissions is significantly less than the proportional increase in GDP due to improvements in energy efficiency (both autonomous and price-induced), autonomous improvements in noncombustion GHG intensities, and expansion of nonfossil electricity generation (Table 5). Consistent with EIA (2017), total electricity production increases by $29.2 \%$, whereas nonfossil electricity

Table 3. Summary results.

\begin{tabular}{|c|c|c|c|c|c|}
\hline & \multirow{2}{*}{$\frac{2011}{\text { Benchmark }}$} & \multicolumn{4}{|c|}{2030} \\
\hline & & BAU & ETS & ETS-vehicles & ETS-all \\
\hline \multicolumn{6}{|l|}{ GDP and welfare } \\
\hline GDP, billion 2011\$ & $1,202.3$ & $2,090.4$ & $2,073.1$ & $2,068.9$ & $2,069.7$ \\
\hline GDP, $\%$ change relative to $\mathrm{BAU}$ & - & - & -0.83 & -1.03 & -0.99 \\
\hline Welfare, billion $2011 \$$ & 634.1 & 1094.8 & 1087.8 & 1086.7 & 1089.0 \\
\hline Welfare, $\%$ change relative to $\mathrm{BAU}$ & - & - & -0.64 & -0.74 & -0.53 \\
\hline \multicolumn{6}{|l|}{$\mathrm{CO}_{2}$ prices, $2011 \$ / \mathrm{tCO}_{2} e$} \\
\hline ETS permits & - & - & 89.9 & 88.4 & 62.9 \\
\hline Domestic offsets & - & - & 15.0 & 15.0 & 0.0 \\
\hline \multicolumn{6}{|l|}{$\mathrm{GHG}$ emissions, $\mathrm{MtCO}_{2} e$} \\
\hline ETS sectors & 491.3 & 575.6 & 292.7 & 294.5 & 557.6 \\
\hline Other sectors & 185.8 & 265.2 & 245.7 & 243.7 & 0.0 \\
\hline Gross emissions & 677.1 & 840.8 & 538.3 & 538.2 & 557.6 \\
\hline International offsets & - & - & -8.6 & -8.5 & -27.9 \\
\hline Net emissions & 677.1 & 840.8 & 529.7 & 529.7 & 529.7 \\
\hline \multicolumn{6}{|l|}{ Energy and vehicles } \\
\hline Electricity production, TWh & 574.6 & 742.6 & 585.3 & 586.9 & 612.5 \\
\hline Primary energy, Mtoe* & 296.4 & 411.5 & 349.0 & 348.4 & 351.2 \\
\hline New car fuel economy, index & 1.00 & 0.80 & 0.80 & 0.41 & 0.78 \\
\hline New car sales & $1,578,716$ & $2,423,438$ & $2,408,983$ & $2,358,427$ & $2,381,808$ \\
\hline
\end{tabular}

Note: *Primary energy from nuclear is based on the amount of heat generated in reactors assuming a $33 \%$ conversion efficiency. For wind, solar and hydro, the primary energy equivalent is the physical energy content of electricity generated.

${ }^{5}$ Our simulated BAU emissions in 2030 are similar to those estimated by Climate Action Tracker (2017) (850.6 $\left.\mathrm{MtCO}_{2} \mathrm{e}\right)$. 
Table 4. GHG emissions, $\mathrm{MtCO}_{2} \mathrm{e}$.

\begin{tabular}{lccrrrrr}
\hline & \multicolumn{2}{c}{2011} & & \multicolumn{3}{c}{2030} \\
\cline { 2 - 2 } \cline { 7 - 8 } & Benchmark & & BAU & ETS & ETS-vehicles & ETS-all \\
\hline $\mathrm{CO}_{2}$, combustion & 582.4 & & 725.8 & 466.9 & 466.7 & 486.7 \\
$\mathrm{CO}_{2}$, noncombustion & 32.0 & & 41.0 & 24.6 & 24.6 & 25.4 \\
$\mathrm{CH}_{4}$ & 29.8 & & 36.5 & 24.4 & 24.3 & 22.9 \\
$\mathrm{~N}_{2} \mathrm{O}$ & 14.3 & & 17.2 & 11.1 & 11.1 & 10.6 \\
F-gases & 18.7 & & 20.4 & 11.4 & 11.4 & 11.9 \\
Gross emissions & 677.1 & & 840.8 & 538.3 & 538.2 & 557.6 \\
International offsets & - & & - & -8.6 & -8.5 & -27.9 \\
Net emissions & 677.1 & & 840.8 & 529.7 & 529.7 & 529.7 \\
\hline
\end{tabular}

Table 5. Electricity production, TWh.

\begin{tabular}{lrrrrrr}
\hline & \multirow{2}{*}{2011} & & \multicolumn{4}{c}{2030} \\
\cline { 2 - 5 } \cline { 5 - 6 } & Benchmark & & BAU & ETS & ETS-vehicles & ETS-all \\
\hline Coal & 230.5 & & 250.0 & 85.0 & 86.1 & 107.2 \\
Gas & 145.4 & & 136.9 & 124.6 & 125.1 & 130.8 \\
Oil & 18.4 & 17.3 & 10.8 & 10.9 & 12.3 \\
Nuclear & 171.0 & & 263.3 & 263.3 & 263.3 & 263.3 \\
Hydro & 5.1 & & 22.0 & 22.0 & 22.0 & 22.0 \\
Wind & 1.0 & & 27.9 & 43.6 & 43.5 & 41.9 \\
Solar & 1.0 & & 13.6 & 21.1 & 21.1 & 20.3 \\
Other & 2.3 & & 11.6 & 14.9 & 14.9 & 14.6 \\
Total & 574.6 & & 742.6 & 585.3 & 586.9 & 612.5 \\
\hline
\end{tabular}

generation increases by $87.7 \%$. The largest absolute increase in electricity generation between 2011 and 2030 occurs for nuclear electricity (92.3 TWh). ${ }^{6}$

The decrease in the fuel economy index for new cars indicates that (in the absence of a fuel economy standard) the number of liters of fuel per kilometer traveled

\footnotetext{
${ }^{6}$ The increase in nuclear generation is consistent with South Korea's 7th Basic Plan for Long-term Electricity Supply and Demand that envisaged 13 new reactors in operation by 2029 (World Nuclear Association, 2019). However, a new government elected in May 2017 announced a policy to phase out nuclear electricity over the next 40 years. Under preliminary plans, the share of nuclear generation in total generation would fall from $31 \%$ in 2019 to $22 \%$ by 2030, but total electricity generation under this pathway is 23\% lower than expected demand (World Nuclear Association, 2019). Additionally, in October 2017, a government committee voted in favor of completing two reactors under construction at the Kori Nuclear Power Plant. Our study does not evaluate uncertainty around the future development of nuclear electricity in South Korea. Instead, we note that as this nation's emissions target is relative to a (hypothetical) BAU in 2030, the impacts of climate policies will be influenced by the generation technologies specified to replace nuclear under BAU conditions.
} 
Table 6. Primary energy, Mtoe.*

\begin{tabular}{lrrrrrr}
\hline & \multicolumn{2}{c}{2011} & & \multicolumn{4}{c}{2030} \\
\cline { 2 - 5 } \cline { 7 - 7 } & Benchmark & & BAU & ETS & ETS-vehicles & ETS-all \\
\hline Coal & 82.46 & & 102.33 & 55.78 & 55.82 & 60.29 \\
Gas & 42.49 & & 54.91 & 47.88 & 48.04 & 47.97 \\
Oil & 127.26 & & 181.00 & 169.91 & 169.08 & 167.76 \\
Nuclear & 43.45 & & 66.92 & 66.92 & 66.92 & 66.92 \\
Hydro & 0.43 & & 1.85 & 1.85 & 1.85 & 1.85 \\
Wind & 0.08 & & 2.34 & 3.66 & 3.65 & 3.51 \\
Solar & 0.08 & & 1.14 & 1.77 & 1.77 & 1.70 \\
Other & 0.19 & & 0.97 & 1.25 & 1.25 & 1.23 \\
Total & 296.44 & & 411.46 & 349.01 & 348.38 & 351.23 \\
\hline
\end{tabular}

Note: *Primary energy from nuclear is based on the amount of heat generated in reactors assuming a 33\% conversion efficiency. For wind, solar and hydro, the primary energy equivalent is the physical energy content of electricity generated.

decreases by $20 \%$ in the BAU scenario relative to the Benchmark case. The number of new cars sales increases by $53.5 \%$ between 2011 and 2030 in the BAU simulation.

In the ETS scenario, constraining GHG emissions relative to BAU reduces GDP by $\$ 17.3$ billion ( $0.83 \%$ of GDP) and welfare, measured as the equivalent variation in consumption expenditure, by $\$ 7.0$ billion $(0.64 \%)$. These estimates do not include any benefits from avoided climate damages. A carbon price, in 2011 dollars, of $\$ 89.9$ per ton of $\mathrm{CO}_{2} \mathrm{e}\left(\mathrm{tCO}_{2} \mathrm{e}\right)$ on emissions from covered sectors is needed to reduce national net GHG emissions by $37 \%$ relative to the BAU scenario. ${ }^{7}$ This carbon price reduces emissions from ETS sectors by $49.2 \%$ (from $575.6 \mathrm{MtCO}_{2} \mathrm{e}$ to $292.7 \mathrm{MtCO}_{2} \mathrm{e}$ ).

As noted earlier, several emissions sources not covered by the ETS are included in a secondary cap-and-trade program to approximate a domestic offset market (with a BAU emissions cap and a limit on the quantity of permits that can be sold to ETS sectors). This mechanism decreases emissions from sources not covered by the ETS by $7.4 \%$ relative to BAU. The price of domestic offsets in the ETS scenario is equal to the price of international offsets $\left(\$ 15 / \mathrm{tCO}_{2} \mathrm{e}\right)$. This is because the use of international offsets $\left(8.6 \mathrm{MtCO}_{2} \mathrm{e}\right.$ or $30.5 \%$ of the total quantity of offsets) is less than the maximum amount allowed (50\% of the quantity of offsets). That is, at a fixed price of $\$ 15 / \mathrm{tCO}_{2}$, $69.5 \%$ of the total allowed offsets is sourced domestically.

Although private transportation is not included in either the ETS or the domestic offset cap-and-trade program, there is a slight improvement in the fuel economy of new cars in the ETS scenario. This is because the price of crude oil is fixed in the model and

\footnotetext{
${ }^{7}$ Comparable to our estimate, Vandyck et al. (2016) project that an emissions price, in 2015 dollars, of $\$ 119 / \mathrm{tCO}{ }_{2}$ is required to meet South Korea's 2030 NDC target.
} 
Table 7. Output changes in 2030 relative to the BAU, 2001\$ and $\%$.

\begin{tabular}{|c|c|c|c|c|c|c|}
\hline & \multicolumn{2}{|c|}{ ETS } & \multicolumn{2}{|c|}{ ETS-vehicles } & \multicolumn{2}{|c|}{ ETS-all } \\
\hline & $\$, \mathrm{~m}$ & $\%$ & $\$, \mathrm{~m}$ & $\%$ & $\$, \mathrm{~m}$ & $\%$ \\
\hline Refined oil products & $-13,929$ & -6.6 & $-15,285$ & -7.2 & $-16,081$ & -7.6 \\
\hline Coal extraction & -133 & -46.6 & -132 & -46.3 & -106 & -37.0 \\
\hline Natural gas & -392 & -69.2 & -388 & -68.7 & -329 & -58.1 \\
\hline Coal electricity & $-10,856$ & -66.0 & $-10,782$ & -65.6 & $-9,391$ & -57.1 \\
\hline Gas electricity & $-1,213$ & -9.0 & $-1,160$ & -8.6 & -600 & -4.4 \\
\hline Oil electricity & $-1,269$ & -37.7 & $-1,251$ & -37.2 & -970 & -28.8 \\
\hline Nuclear electricity & 0 & 0.0 & 0 & 0.0 & 0 & 0.0 \\
\hline Hydroelectricity & 0 & 0.0 & 0 & 0.0 & 0 & 0.0 \\
\hline Wind electricity & 1,219 & 56.3 & 1,213 & 56.0 & 1,086 & 50.1 \\
\hline Solar electricity & 1,580 & 55.2 & 1,571 & 54.9 & 1,406 & 49.1 \\
\hline Other electricity & 317 & 28.9 & 315 & 28.8 & 290 & 26.5 \\
\hline Electricity transmission and distrib. & $-2,954$ & -23.9 & $-2,917$ & -23.6 & $-2,335$ & -18.9 \\
\hline Agriculture, forestry, and fishing & -708 & -0.9 & -679 & -0.9 & -958 & -1.2 \\
\hline Other mining & -303 & -5.4 & -302 & -5.3 & -223 & -3.9 \\
\hline Chemical, rubber, and plastic products & $-22,271$ & -6.5 & $-21,712$ & -6.4 & $-16,767$ & -4.9 \\
\hline Nonmetallic minerals & $-3,285$ & -5.9 & $-3,285$ & -5.9 & $-2,445$ & -4.4 \\
\hline Iron and steel & $-16,130$ & -5.6 & $-16,050$ & -5.6 & $-11,440$ & -4.0 \\
\hline Nonferrous metals & $-3,648$ & -4.9 & $-3,582$ & -4.8 & $-2,564$ & -3.4 \\
\hline Fabricated metals products & $-2,658$ & -2.0 & $-2,541$ & -1.9 & $-1,811$ & -1.4 \\
\hline Food processing & $-1,704$ & -1.2 & $-1,565$ & -1.1 & $-1,441$ & -1.0 \\
\hline Wood and paper products & $-1,473$ & -2.0 & $-1,470$ & -2.0 & $-1,207$ & -1.7 \\
\hline Textiles, clothing, and footwear & $-3,948$ & -4.6 & $-3,909$ & -4.6 & $-2,885$ & -3.4 \\
\hline Motor vehicles and parts & $-1,460$ & -0.6 & 5,234 & 2.3 & $-1,987$ & -0.9 \\
\hline Other transportation equipment & $-3,281$ & -3.1 & $-4,324$ & -4.1 & $-1,420$ & -1.4 \\
\hline Electronic equipment & $-7,184$ & -2.0 & $-7,625$ & -2.1 & $-3,457$ & -0.9 \\
\hline Other machinery and equipment & $-1,370$ & -0.4 & $-2,517$ & -0.8 & 623 & 0.2 \\
\hline Other manufacturing & $-1,235$ & -1.7 & $-1,112$ & -1.5 & -766 & -1.0 \\
\hline Commercial transportation & $-3,321$ & -1.5 & $-4,086$ & -1.8 & $-13,818$ & -6.1 \\
\hline Wholesale and retail trade & $-4,360$ & -1.0 & $-3,914$ & -0.9 & $-3,390$ & -0.8 \\
\hline Water collection and distribution & -321 & -2.6 & -312 & -2.5 & -243 & -2.0 \\
\hline Communications & -599 & -0.6 & -548 & -0.6 & -425 & -0.5 \\
\hline Construction & $-2,077$ & -0.7 & $-2,383$ & -0.8 & $-1,687$ & -0.5 \\
\hline Other services & $-5,748$ & -0.5 & $-6,446$ & -0.5 & $-4,703$ & -0.4 \\
\hline
\end{tabular}

the inclusion of oil refining in the ETS increases the price of refined oil, causing a price-induced substitution toward more fuel-efficient vehicles. The ETS reduces the number of new car sales by $14,455(0.6 \%)$ relative to BAU.

Changes in output relative to BAU for the ETS and ETS-Vehicles scenarios are reported in Table 7. In the ETS scenario, output for all sectors decreases except for low-carbon electricity sectors without regulatory constraints (solar electricity, wind electricity, and other electricity). The largest proportional reductions in output occur in energy sectors (e.g., coal electricity generation). Among nonenergy sectors, the 
chemical, rubber and plastic products sector experiences the largest proportional output decrease (6.5\%). Absolute decreases in output are largest for chemical, rubber and plastic products; iron and steel; refined oil products; and coal electricity. The output decrease for motor vehicles and parts $(0.6 \%)$ is small relative to those for other sectors, as the GHG intensity for this sector is relatively low. Consequently, the negative impact of rising energy costs is partially offset by reduced demand for capital and labor from most other sectors. Changes in exports relative to BAU (not reported) follow a similar pattern to changes in output. Proportional exports decreases are largest for chemical, rubber and plastic products $(8.5 \%)$, iron and steel $(9.2 \%)$, and nonmetallic minerals $(14.7 \%)$. The decline in exports of motor vehicles and parts is $0.6 \%$.

When vehicle fuel economy standards are added to the ETS policy (ETS-vehicles), reduced emissions from own-supplied transportation allow more emissions from sectors covered by the ETS policy $\left(294.5 \mathrm{MtCO}_{2} \mathrm{e}\right.$ in the ETS-vehicles scenario compared with $292.7 \mathrm{MtCO}_{2} \mathrm{e}$ in the ETS scenario). This results in a small reduction in the $\mathrm{CO}_{2}$ price but increases the GDP cost (by $\$ 4.2$ billion) and welfare cost (by $\$ 1.1$ billion) of meeting the economy-wide reduction in emissions. By increasing the cost of motor vehicles, the fuel economy standard also decreases new car sales by 50,555 ( $2.1 \%$ of new car sales under BAU).

In the ETS-vehicles scenario, output changes for all sectors except motor vehicles and refined oil are similar to those in the ETS scenario. The fuel economy standard has two opposing impacts on the output of the motor vehicles sector. First, by increasing the costs of new cars, the standard decreases the demand for motor vehicles (as illustrated by the decline in new car sales). Secondly, for each kilometer of travel, the standard forces consumers to spend more on powertrain capital and less on fuel, which increases demand for outputs from the motor vehicles sector. The $2.3 \%$ increase in motor vehicle output relative to BAU in the ETS-vehicles (compared with a $0.6 \%$ decrease in the ETS scenario) indicates that the powertrain-share effect dominates the cost effect. The forced decrease in fuel expenditure per kilometer traveled in the ETSvehicles scenario leads to a larger decrease in output of refined oil products relative to BAU (7.2\%) than in the ETS scenario (6.6\%).

In the ETS-all scenario, as expected, the carbon price $\left(\$ 62.9 / \mathrm{tCO}_{2}\right)$ and the welfare cost of meeting the NDC goal is lower than in other policy scenarios. Due to the lower carbon price, relative to other ETS scenarios, there is more electricity from coal and gas and less from wind and solar. There are smaller reductions in the output of energyintensive sectors included in the KETS (e.g., relative to BAU, output of chemical, rubber, and plastic products decreases by $4.9 \%$ in the ETS-all scenario and $6.5 \%$ in the ETS scenario). Conversely, there is a large reduction in the output of the commercial transportation sector $(6.1 \%)$, an energy-intensive sector that was excluded from carbon pricing in other ETS scenarios. Relative to the ETS scenario, output of motor vehicles and parts falls in the ETS-all scenario as the inclusion of household fuel purchases in the ETS reduces the demand for vehicles. 


\section{Conclusions}

South Korea's NDC has been rated as "Inadequate" by the Climate Action Tracker (2017) on the basis that the proposed 2030 target would allow emissions to be more than double the 1990 level. In contrast, the EU is rated "Insufficient", a higher rating. These ratings are against what is required to achieve the $1.5^{\circ} \mathrm{C}$ or $2.0^{\circ} \mathrm{C}$ target of the Paris agreement. Essentially no country of any significance has sufficient objectives by this rating, hardly a surprise given that a variety of studies have shown that the Paris agreement is insufficient to achieve the $2^{\circ}$ target. However, the comparison of South Korea and the EU illustrates the extra challenge of countries like South Korea that are in a rapid growth phase. The carbon price in the EU is currently about 7.6 Euro (\$9) per ton (in current dollars), and its 2030 target can probably be achieved with only a modest increase. However, we estimate that the South Korean carbon price would need to be nearly $\$ 90$ (in 2011 dollars), making full use of offsets their legislation allows. From the perspective of the GHG price required, the South Korean NDC is among the most ambitious. Still the GDP and welfare costs remain less than $1 \%$. That highlights an advantage of the country's recent rapid growth - its industrial base is relatively new and energy-efficient, and so even with a higher carbon price the cost remains a small share of the economy.

The economic prescription for achieving emissions goals at least cost is to allow the market to seek out the least cost abatement options by establishing a uniform carbon price and avoiding duplicative policies. Most countries do not heed this advice and choose a mix of policies. Very often countries regulate vehicle emissions through GHG or fuel standards for new vehicle sales, as South Korea is doing. There are a variety of economic arguments as to why these are less efficient than including vehicle fuel sales in a cap-and-trade system. For one, they provide incentives only for new vehicle sales, and so the effect of the policy is small in the short run until more of the fleet is replaced. A carbon pricing mechanism affects use of existing vehicles as well as the choice of new vehicle purchase and so works to reduce emissions through vehicle choice, miles driven, and vehicle maintenance. Then a second inefficiency is that once the more efficient vehicle is purchased under a fuel or GHG standard, the cost of driving is lower, and so it can lead to increases in miles traveled, offsetting some of the apparent gain from more efficient vehicles.

In some previous studies comparing vehicle standards and cap and trade, a quite large additional cost was incurred when vehicle standards were imposed (Rausch and Karplus, 2014; Paltsev et al., 2016). These studies focussed on costs of standards in the EU and the US, generally for the period up to about 2030, similar to our South Korea study. However, in the case of South Korea, we see some additional cost but much less than in these previous studies even though the basic structure of the model applied here is similar. There are a few reasons for this difference. First, the scenario construction among these studies was different. Rausch and Karplus (2014) compared achieving a given reduction via technology standards for vehicles and power generation versus 
achieving the same emissions level with an economy-wide emissions cap; that both broadened the coverage from two sectors to the entire economy and substituted a more efficient policy mechanism. Here we are comparing a cap and trade that does not include transportation with a policy that adds transportation via fuel standards. In principle, by broadening the policy to include more sectors, it should reduce the cost, but instead the cost is increased - clear evidence of an inefficiency (partly because of the mechanism itself, and possibly also because the standard is more stringent than it should be). The Paltsev et al. (2016) study for the EU imposed the standards on top of a cap that included the transportation sector, a slightly different scenario design. In our comparable scenario, which imposed a cap on the transportation sector instead of the vehicle standards, we get a more similar result to the Paltsev et al. (2016) study, with the welfare cost lowered by about $30 \%$ compared with controlling emissions from vehicles with vehicle standards.

A second reason for the smaller cost add-on is due to the fact that the carbon price needed to meet the target for South Korea is much higher than the near-term carbon price in, for example, the EU. The South Korean carbon price level in 2030 would, by itself, create incentives to adopt more efficient vehicles, and so the fuel standard is pushing in the right direction, albeit inefficiently. Paltsev et al. (2015), using a recursive dynamic model and comparing regulatory approaches to cap and trade, demonstrated that as the GHG price rose, eventually the added cost of the fuel standards largely disappeared.

Of course, our estimates depend on the added vehicle costs related to improving efficiency, relative to the cost of abating elsewhere in the economy, but our formulation here is similar to that in the earlier cited studies.

Our results show impacts on sectors generally as expected: fossil fuel-dependent electricity production drops substantially, especially coal, and nonfossil electricity expands. Production in nearly all other sectors declines. The decline is in the range of 4.9-6.6\% for more energy-intensive sectors such as iron and steel and chemicals, rubber and plastics. For other less energy-intensive sectors, the decline in production is on the order of $0.5-2.0 \%$. The value of production of motor vehicles and parts is one sector that actually increases under the fuel standards scenario. While we estimate that the number of vehicles sold falls, the cost of vehicles rises and so the total value of sales actually increases by a bit over $2 \%$ whereas under the cap and trade the value of vehicle sales fall by about $0.6 \%$. Vehicle sales and the value of sales fall when the sector's emissions are covered by the cap-and-trade measure instead of the vehicle standards.

\section{Acknowledgments}

The authors gratefully acknowledge financial support from the General Motors Company. The MIT Joint Program on the Science and Policy of Global Change is funded by a consortium of industrial sponsors and Federal grants. For a complete list 
of sponsors see http://globalchange.mit.edu/sponsors. The findings in this study are solely the opinions of the authors.

\section{References}

Aguiar, A, B Narayanan and R McDougall (2016). An overview of the GTAP 9 Data Base. Journal of Global Economic Analysis, 1(1), 181-208.

Aldy, J, W Pizer, M Tavoni, LA Reis, K Akimoto, G Blanford, C Carraro, LE Clarke, J Edmonds, GC Iyer, HC McJeon, R Richels, S Rose and F Sano (2016). Economic tools to promote transparency and comparability in the Paris Agreement, Nature Climate Change, 6, 1000-1004.

Armington, PS (1969). A theory of demand for products distinguished by place of production. IMF Staff Papers, 16, 159-176.

Capros, P, D Van Regemorter, L Paroussos and P Karkatsoulis (2013). GEM-E3 Model Documentation, Joint Research Centre Technical Report, European Commission, Seville, Spain. Available at https://ec.europa.eu/jrc/en/gem-e3/model.

Chen, Y-HH, S Paltsev, J Reilly, J Morris, V Karplus, A Gurgel, N Winchester, P Kishimoto, É Blanc and M Babiker (2017). The MIT Economic Projection and Policy Analysis (EPPA) Model: Version 5, Joint Program on the Science and Policy of Global Change, Technical Note 16, Massachusetts Institute of Technology, Cambridge, MA. Available at https:// globalchange.mit.edu/publication/16620.

Climate Action Tracker (2017). South Korea, updated as of 6 November 2017 Available at http://climateactiontracker.org/countries/southkorea.html.

Cossa, P (2004). Uncertainty analysis of the cost of climate policies. Master of Science Thesis, Technology and Policy Program, MIT, Cambridge, Massachusetts. Available at https:// dspace.mit.edu/handle/1721.1/30074.

Dirkse, SP and MC Ferris (1995). The PATH Solver: A non-monontone stabilization scheme for Mixed Complementarity Problems. Optimization Methods and Software, 5, 123-156.

EIA (2017), International Energy Outlook 2017. US Energy Information Administration, Washington DC. Available at https://www.eia.gov/outlooks/ieo/ieo_tables.php. Accessed on 5 October 2017.

Fawcett, AA, GC Iyer, LE Clarke, JA Edmonds, NE Hultman, HC McJeon, J Rogelj, R Schuler, J Alsalam, GR Asrar, J Creason, M Jeong, J McFarland, A Mundra and W Shi (2015). Can Paris pledges avert severe climate change? Science, 350(6265), 1168-1169.

Fragkiadakis, K, L Paroussos, N Kouvaritakis and P Capros (2012). A Multi-country econometric estimation of the constant elasticity of substitution. Paper presented at the Final WIOD Conference: Causes and Consequences of Globalization, Groningen, The Netherlands. Available at http://www.wiod.org/conferences/groningen/Paper_Fragiadakis_et_al.pdf.

Greenhouse Gas Inventory and Research Center of Korea (2014). First Biennial Update Report of the Republic of Korea, Government Publications Registration Number 11-1480745000009-01.

Hertel, T, D Hummels, M Ivanic and R Keeney (2007). How confident can we be of CGEBased assessments of free trade agreements? Economic Modelling, 24(4), 611-635.

ICAO-CAEP (International Civil Aviation Organization Committee on Aviation Environmental Protection) (2016). Results of Technical Analyses by CAEP, ICAO Environment Advisory Group Meeting (EAG/15), January 20-21. https://www.icao.int/Meetings/HLM-MBM/ Documents/EAG15_CAEP\%20Technical\%20Analyses.pdf. 
ICCT (International Council on Clean Transportation) (2015). South Korea fuel economic and greenhouse gas standards for new light-duty vehicles (2016-2020), Policy Update. Available at http://www.theicct.org/sites/default/files/publications/S.Korea\%20FE\%20GHG \%20Policy\%20Update_vFinal.pdf.

Irfanoglu, I and D van der Mensbrugghe (2015). Development of the Version 9 Non- $\mathrm{CO}_{2} \mathrm{GHG}$ Emissions Database, Global Trade Analysis Project Resource 7813, Purdue University, West Lafayette, IN. Available at https://www.gtap.agecon.purdue.edu/resources/download/7813. pdf. Accessed on 11 November 2017.

Jacoby, H, Y-H Chen and B Flannery (2017). Informing transparency in the Paris Agreement: The role of economic models. Climate Policy, 17(7), 873-890.

Karplus, V, S Paltsev, M Babiker and J Reilly (2013). Applying engineering and fleet detail to represent passenger vehicle transport in a computable general equilibrium model. Economic Modelling, 30, 295-305.

Lanz, B and T Rutherford (2016). GTAPinGAMS: Multiregional and small open economy models. Journal of Global Economic Analysis, 1(2), 1-77.

Ministry of Environment (2014). 2020 CAFE_CO ${ }_{2}$ regulation, MOE Notification 2014-235.

Ministry of the Environment (South Korea) (2017). National greenhouse gas reduction goals. Available at http://eng.me.go.kr/eng/web/index.do?menuId=201. Accessed on 21 November 2017.

OECD (2017). GDP long-term forecast (indicator). doi:10.1787/d927bc18-en. Accessed on 5 October 2017.

Orlov, A and A Aaheim (2017). Economy-wide effects of international and Russia's climate policies. Energy Economics, 68, 466-477.

Paltsev, S, J Reilly, HD Jacoby, RS Eckaus, J McFarland, M Sarofim, M Asadooria and M Babiker (2005). The MIT Emissions Prediction and Policy Analysis (EPPA) Model: Version 4. Joint Program on the Science and Policy of Global Change, Report No. 125, Massachusetts Institute of Technology.

Paltsev, S, Y-H Chen, V Karplus, P Kishimoto, J Reilly, A Loeschel, K von Graevenitz and S Koesler (2016). Reducing CO2 from cars in the European Union. Transportation, online first doi:10.1007/s11116-016-9741-3. Available from http://link.springer.com/article/ 10.1007\%2Fs11116-016-9741-3.

Paltsev, S, V Karplus, H Chen, I Karkatsouli, J Reilly and H Jacoby (2015). Regulatory control of vehicle and power plant emissions: How effective and at what cost? Climate Policy, 15(4), 438-457.

Peters, J (2016). The GTAP-Power Data Base: Disaggregating the electricity sector in the GTAP Data Base. Journal of Global Economic Analysis, 1(1), 209-250.

Rausch, S and VJ Karplus (2014). Markets versus regulation: The efficiency and distributional impacts of U.S. Climate Policy Proposals. Energy Journal, 35(S1), 199-227. https://doi.org/ 10.5547/01956574.35.SI1.11.

Rausch, S and M Mowers (2014). Distributional and efficiency impacts of clean and renewable energy standards for electricity. Resource and Energy Economics, 36(2), 556-585.

Rosenthal, ER (2012). GAMS - A User's Guide. GAMS Development Corporation, Washington, DC.

Rutherford, TF (1995). Extension of GAMS for complementary problems arising in applied economic analysis. Journal of Economics Dynamics and Control, 19(8), 1299-1324.

Singh, A, N Winchester and VJ Karplus (2017). Evaluating India's climate targets: The implications of economy-wide and sector specific policies, Joint Program on the Science and 
Policy of Global Change, Report No. 327, Massachusetts Institute of Technology, Cambridge, MA. Available from https://globalchange.mit.edu/publication/16924.

Vandyck, T, K Keramidas, B Saveyn, A Kitous and Z Vrontisi (2016). A global stocktake of the Paris pledges: Implications for energy systems and economy. Global Environmental Change, 41, 46-63.

World Nuclear Association (2019). Nuclear Power in South Korea, London, United Kingdom. Available at http://www.world-nuclear.org/information-library/country-profiles/countries-os/south-korea.aspx.

Yongrok, C, Y Liu and H Lee (2017). The economy impacts of Korean ETS with an emphasis on sectoral coverage based on a CGE approach. Energy Policy, 109, 835-844. 